\title{
Conservation of gibbons in Yunnan Province, China
}

\author{
Elliott H. Haimoff, Yang Xiao-Jun, He Swing-Jing and Chen Nan
}

Three gibbon species inhabit the tropical and subtropical forests in China, all of which occur in Yunnan Province: the crested gibbon Hylobates concolor, lar gibbon $\boldsymbol{H}$. lar, and hoolock gibbon $H$. hoolock. As a result of deforestation and over-hunting, all three species are gravely endangered in China and may be on the verge of extinction; they are now considered to be the nation's rarest animals. A recent census and survey of crested gibbons in Yunnan Province, partly funded from FFPS's Oryx 100\% Fund, revealed new information on the distribution, status and conservation of gibbons in China. The authors made recommendations for future conservation measures, and these are now being considered by the Chinese Academy of Sciences and the Chinese Government.

For several decades the slash-and-burn cultivation and the regular hunting carried out by the inhabitants of southern China, in addition to the recent expansion of the rubber industry in this region due to the favourable climate and soil conditions, have resulted in a vast and continuous reduction of primate population numbers and their forest habitats (Zhang et al., 1981; Tan, 1985). All Chinese provinces that contain wild primates now have only patches of isolated forests left in various states of disturbance, having been hardest hit during the Cultural Revolution of the 1960s and 1970s, when much of the forests and wildlife was devastated as a result of economic growth and development (Tan, 1985).

Gibbons (Hylobates spp.) are small arboreal apes, inhabiting the tropical and subtropical forests of South East Asia. Since all gibbon species are strictly arboreal and generally restricted to good quality or undisturbed primary forests, they are by far the most vulnerable of all primate species to habitat destruction. In addition, many rural people in China believe that the meat and bones of these animals have high medicinal value as a tonic, and people in western Yunnan still use these animal by-products as a 168 cure for epilepsy (Tan, 1985). For these reasons, gibbons have been heavily hunted throughout their range for the past several decades.

There are currently three gibbon species in China: the lar gibbon $H$. lar, hoolock gibbon $H$. hoolock, and the crested gibbon $H$. concolor. The first two are confined, in China, to Yunnan Province, while the third is found in Yunnan and on Hainan Island in Guangdong Province (see Tan, 1985). Only 1000 years ago the crested gibbons inhabited at least 10 Chinese provinces in tropical and subtropical forests as far north as $33^{\circ}$ throughout central and southern China (van Gulik, 1967; Gao et al., 1981). The crested gibbon on Hainan Island has been virtually wiped out as a result of the expansion of the rubber industry and hunting, with only about 30-40 animals left in two of the remotest mountain peaks (Jiangfengling and Bawangling), which are isolated from each other (Xu et al., 1983; Liu et al., 1984). The recent establishment of fully protected game reserves and nature sanctuaries in these two areas for the specific purpose of conserving these primates is a positive note of hope.

Because of their restricted range in parts of Oryx Vol 21 No 3, July 1987 
Yunnan Province, combined with the continued hunting pressures and deforestation of their habitat, all three gibbon species have been placed on the list of top-priority protected animals in China (Quan et al., 1981; Gao et al., 1981; Tan, 1985). As there have never been any systematic surveys to determine their status, or even an investigation of local reports of the areas that gibbons were believed to inhabit, there was concern about their population numbers and appropriate conservation measures.

During a recent field study of the crested gibbons in Yunnan Province (Haimoff et al., 1987a,b) new information became available regarding the status of this species, as well as a great deal of additional information on the status of the lar and hoolock gibbons. Based on the findings of this project, recommendations regarding the conservation of gibbons were made to the Chinese Academy of Sciences and the Chinese Government, and these are also presented.

\section{Crested gibbons}

\section{Distribution}

There are currently believed to be two subspecies of crested gibbon in Yunnan Province (see Delacour, 1951; Groves, 1972): the whitecheeked gibbon $H$. c. leucogenys, inhabiting only a small strip of the extreme southern portion of Yunnan Province, and the black-crested gibbon $H$. c. concolor, currently inhabiting central, western, and southern Yunnan Province. A population of black-crested gibbons that was recently discovered between the Mekong and Salween rivers is believed to differ significantly from the black-crested gibbon population on the east side of the Mekong river and is now being considered as a new crested gibbon subspecies (Wang Ying-Xiang, pers. comm.) (Figure 1).

All populations of crested gibbons are now restricted to isolated game reserves and other patches of forests in Yunnan (Figure 1). These localities were determined by the collection of specimens by Li and Lin (1983), Wang YingXiang (pers. comm.), and during the current study by Haimoff et al. (1987) and Yang Dehua (in prep.). They may also occur in some other forest patches in south-eastern Yunnan near the Gibbons in Yunnan Province, China border with Vietnam, but reports from these locations are not precise and still remain to be confirmed.

White-cheeked gibbons are found throughout most of Laos and Vietnam, but occur in China only in Xishuangbanna in the extreme southern tip of Yunnan. This subspecies seems to inhabit only good quality tropical rain forests, and the northern limit of its range seems to be the transition point between the tropical and subtropical forests between the Mekong and Black rivers in Yunnan. Most of the area in Xishuangbanna has been cleared to make way for rubber plantations and agricultural farmlands;

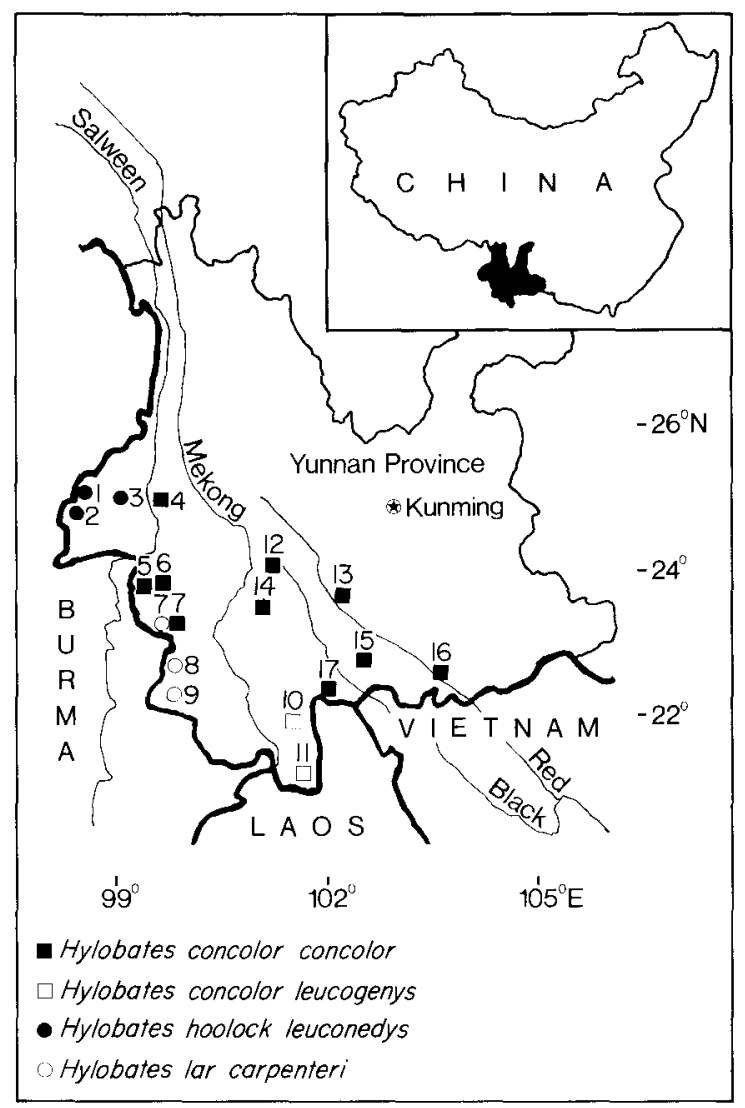

Figure 1. A map of Yunnan Province, People's Republic of China, illustrating the distribution of gibbons throughout the province. The numbered locations are as follows:

(1) Guyong; (2) Yingiiang; (3) Tengchong; (4) Baoshan;

(5) Gengma; (6) Shuangiiang; (7) Cangyuan; (8) Ximeng;

(9) Menglian; (10) Mengluen; (11) Mengla; (12) Jingdong;

(13) Xingping; (14) Zhenyuan; (15) Luchun; (16) Pingbian; (17) Jiangcheng. 


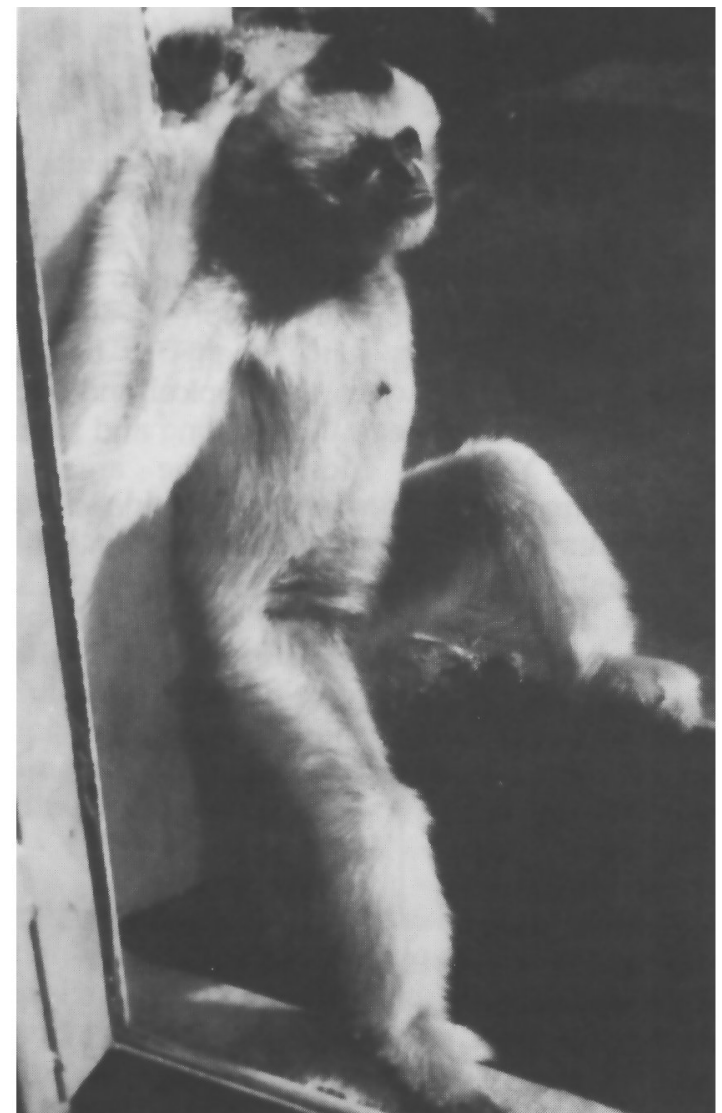

An adult female white-cheeked gibbon Hylobates concolor leucogenys in the Beijing Zoo, where a captive-breeding programme is under consideration (Elliott Haimoff).

in addition, heavy hunting pressures on these animals continue (Yang Dehua, pers. comm.). Although this subspecies was collected in four counties in Xishuangbanna in the 1960s and 1970 s by Li and Lin (1983), it is now restricted to two game reserves in two counties (Mengla and Mengluen) (Figure 1), and a recent faunal survey by Yang Dehua (in prep.) could find no trace of gibbons anywhere in Mengluen county. They were found to be very rare in Mengla Game Reserve on the border with Laos (Yang Dehua, in prep.), but the politically sensitive nature of the area prevented and still prevents any long-term surveys.

The newly discovered population of black crested gibbons on the west side of the Mekong river is highly significant. This population inhabits 170 only the mountainous subtropical forests between the Salween and Mekong rivers. The southern limit to the distribution of this population is the transition between the tropical and subtropical forests in southern Yunnan, while the northern limit seems to be the snowcovered pine forests in the Trans-Himalayan Range in north-western Yunnan. It is interesting to note that local reports from Cangyuan Game Reserve (no. 7 in Figure 1) indicate that the crested and lar gibbons inhabit the same game reserve and overlap in their distribution; however, the lar gibbons are generally restricted to the lowland tropical rain forests near the river, while the crested gibbons inhabit only the subtropical forests at the higher elevations in the rugged mountainous terrain.

\section{Status}

Haimoff et al. $(1987 \mathrm{a}, \mathrm{b})$ revealed that this is the only polygynous gibbon species (all others are monogamous), with an average group size of seven to eight comprising one adult male, one to four adult females, and offspring of various ages. Before our survey, Tan (1985) believed there were no more than about 20 groups of blackcrested gibbons left in China, but we suggested a population of well over 200 groups in one game reserve alone (Wuliang Mountain Game Reserve) (Figure 2) (Haimoff et al., 1987a), and while this subspecies is highly endangered, it is not now believed to be on the brink of extinction in China. The mountainous regions in the four counties between the Salween and Mekong rivers, where the potentially new crested gibbon subspecies is found, includes one large and wellprotected game reserve in Cangyuan, and local reports suggest that there may be as many as $100-500$ groups in each of these sites.

The white-cheeked gibbons have been hunted so heavily in Xishuangbanna over the last few years that they are now believed to number no more than about 50 animals (Yang Dehua, in prep.).

\section{Lar gibbons}

\section{Distribution}

This gibbon species has a wide distribution throughout Thailand, West Malaysia and Oryx Vol 21 No 3, July 1987 
northern Sumatra. The discovery of the lar gibbon in Yunnan by Li and Lin (1983) added a new species to China's faunal records, and represents the northern limit to the geographic range of this species. Groves (1968) indicated that the population of lar gibbons inhabiting northern Thailand, eastern Burma, and now presumably Yunnan Province, is a different subspecies, $H$. lar carpenteri, from the populations of the Malay Peninsula and Sumatra. The western and eastern borders of its distribution in China appear to be the Salween and Mekong rivers, respectively, while the northern limit seems to be correlated with the end of the lowland tropical rain forests and the beginning of the mountainous subtropical forests in southwestern Yunnan (Figure 1). These gibbons are found only in one fully protected game reserve in Cangyuan county, and their current status in the other two counties, where they were collected and seen by Li and Lin (1983), Yang Dehua (in prep.), and Wang Sung (pers. comm.), seems to be very tenuous. Reports suggest that the lar gibbons may now be completely absent from the area around Ximeng and Lancang (no. 8 in Figure 1) (Tan, 1985).

\section{Status}

There have been no other documented accounts or even any local reports on the total population number of this species in China, and its status remains uncertain; however, an estimate of a maximum number of about 50-100 groups seems reasonable. Since this species appears to be confined to the lowland areas, which are those most affected by habitat destruction and hunting, it is in grave danger of extinction in China.

\section{Hoolock gibbons}

\section{Distribution}

The study by Groves (1967) has shown that there are two well-defined subspecies: the western hoolock gibbon, $H$. h. hoolock, which is found between the Brahmaputra and Chindwin rivers in India, Bangladesh, and Burma, and the eastern hoolock gibbon, $H$. $h$. leuconedys, which is found between the Chindwin and Salween rivers in Burma and China. The eastern limit of the hoolock gibbon's range is generally regarded to extend up to the extreme western tip of Yunnan Province (Figure 1). The hoolock gibbon has been collected from sites in three counties to the west of the Salween river in Yunnan ( $\mathrm{Li}$ and $\mathrm{Lin}, 1983$ ), but reports by Tan (1985) that this species also occurs on the eastern side of the Salween in Baoshan (no. 4 in Figure 1) are inaccurate and confused with the occurrence of the crested gibbons (Yang Dehua, in prep.). Recent local reports of sightings of this species by Yang et al. (1982) indicated clearly that the hoolock gibbon now seems to be either completely gone or extremely rare in all places in Yunnan other than in Yingjiang county. They may now be restricted to only the Tongbiguan Game Reserve in Yingjiang county on the border with Burma.

\section{Status}

It is clear from local reports of western Yunnan, in addition to recent general faunal surveys in the

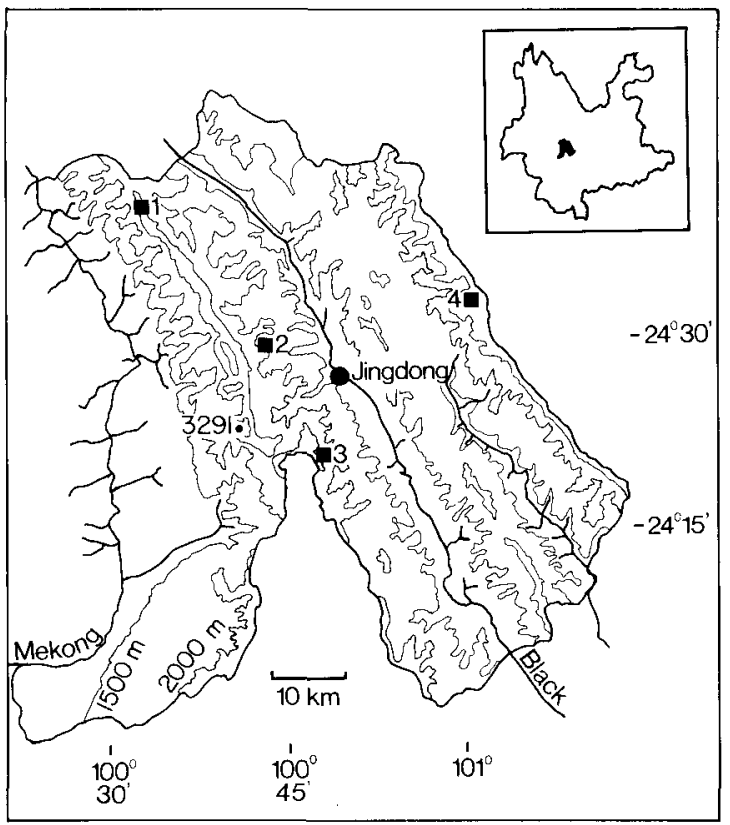

Figure 2. A map of Jingdong county, Yunnan Province. The mountain range between the Mekong and the Black rivers above $2000 \mathrm{~m}$ is the recently established Wuliang Mountain Game Reserve, while the mountain range to the east of the

Black river is the Ailao Mountain Game Reserve. The numbered locations are the sites visited during a recent census of black-crested gibbons by Haimoff et al. (1987a) where gibbons were found in substantial numbers, which are: (1) Shin Chuen; (2) Wenpu; (3) Bayenza; and (4) Xujiaba. 
area by various Chinese scientists, that the population of this gibbon species is rapidly dwindling and is in grave danger of extinction in China. At a recent conference in China, it was suggested that there are no more than about 50 animals left in China (see Tan, 1985). While this number may seem somewhat low, and even if this species is now limited in its distribution to a single game reserve, it would seem that, as a result of the unusually heavy hunting pressures in this part of the province, their numbers in China could be no more than about 100-200 animals.

\section{Recommendations for conservation}

Government policy in China during the 1960s and 1970 s resulted in the massive destruction of habitats suitable for gibbons, and this was accompanied by continuous hunting pressures on these animals in Yunnan Province. However, the Government now acknowledges both the severity of the problem and the inadequacies of previous conservation measures, and is prepared to take action. Recent policy decisions have been taken to establish various forest tracts as fully protected game reserves (e.g. Wuliang Mountain Game Reserve - see Figure 2), and strict laws have been passed forbidding the export of gibbons from China. Perhaps the most important next step in the conservation of gibbons would be to establish a fully protected game reserve or nature sanctuary in Yongde county, where the new population of crested gibbons was found.

Several recommendations for the conservation of gibbons resulted from the recent census and survey in Yunnan Province by Haimoff et al. (1987a). Since the real dangers to the gibbons in China are over-hunting and deforestation, solutions to the gibbon conservation problem might include: (a) passing stronger legislation against hunting gibbons, perhaps making it an offence punishable by a prison sentence; (b) making the cutting down of trees in a game reserve an offence liable to a prison sentence; (c) making it illegal to enter a reserve with a loaded gun or other means of killing rare and endangered animals; and (d) establishing development zones where logging companies already operate, so that careful selective logging following sound ecological guidelines and censuses would be permitted.

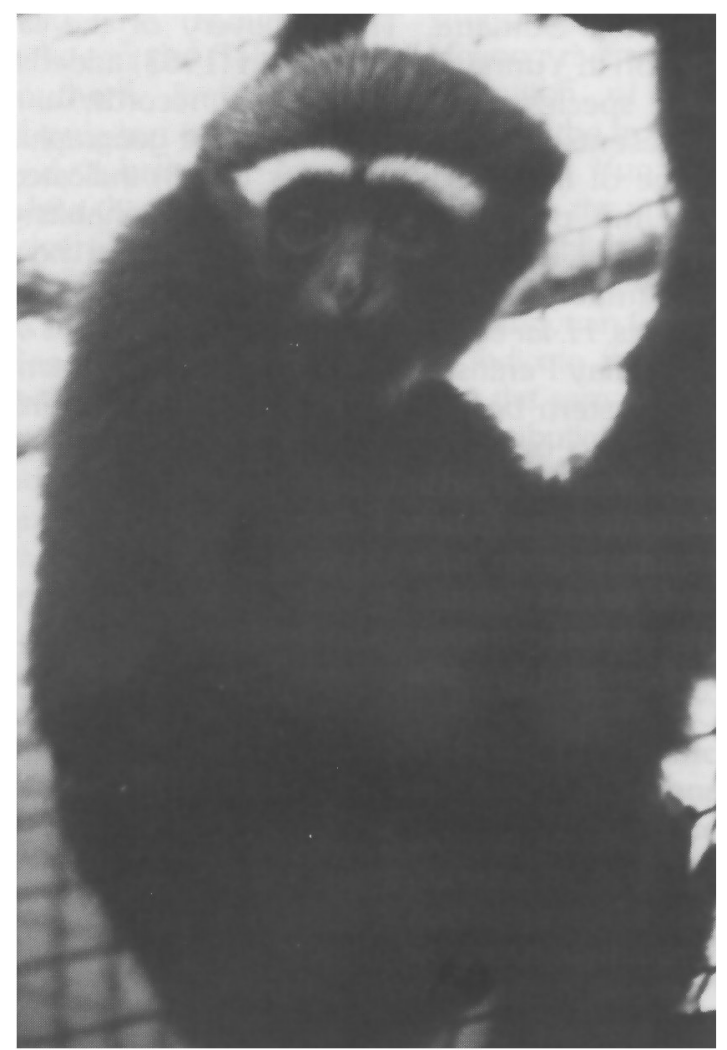

A young male hoolock gibbon (Hylobates hoolock leuconedys), which was confiscated as a pet and is currently held at the Kunming Institute of Zoology (Elliott Haimoff).

Another important step in the conservation of gibbons would be to educate scientists and the general population that the gibbons are a Chinese national treasure, and that they should be saved instead of being hunted and killed for food or medicinal purposes. This conservation message could be spread by newspaper articles, radio broadcasts, school projects, poster campaigns and specially designed postage stamps.

To gain a better idea of the total population size of this species it is important to conduct further census and survey studies of gibbons in other parts of Yunnan Province. It would also be appropriate eventually to establish a long-term captive-breeding programme where gibbons could be bred in captivity and released into suitable forest tracts once laws and attitudes regarding the conservation of gibbons have changed.

Oryx Vol 21 No 3, July 1987 


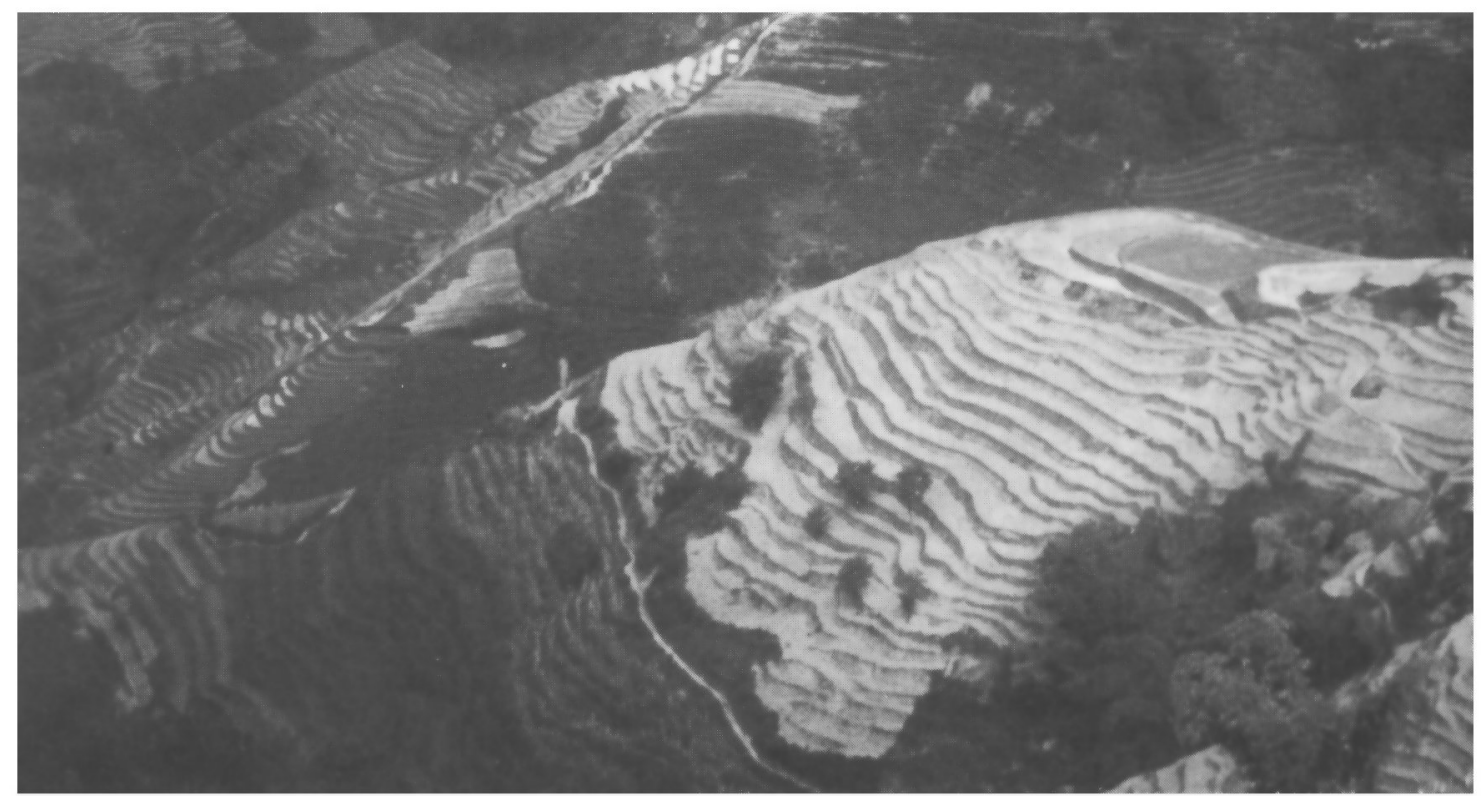

Hillside terraced rice paddies within the Ailao Mountain Game Reserve, illustrating that habitat destruction is extensive even within reserves (Ellott Haimoff).

\section{Acknowledgments}

We are deeply grateful to Professor Shi Liming, Mr Li Chaoda, and $\mathrm{Mr}$ Gi Weighi of the Kunming Institute of Zoology, for their support of the census project in Yunnan Province. We wish to express our deepest appreciation to the Chinese Academy of Science and the Ministry of Forestry for their assistance during this gibbon project. We thank Drs David Chivers, Jay Russell, and Robyn Tell for their critical reading and invaluable comments on the manuscript. This study was funded by the Fauna and Flora Preservation Society, L. S. B. Leakey Foundation, Chinese Academy of Science, and UCLA.

\section{References}

Delacour, J. 1951. la Systematique des gibbons indochinois. Mammalia, 15, 118-123.

Gao, Y.-T., Wen, H.-R. and He, Y.-H. 1981. The change in historical distribution of Chinese gibbons (Hylobates). Zoological Research, 2, 1-8.

Groves, C. 1967. Geographic variation in the hoolock or white-browed gibbon (Hylobates hoolock Harlan 1834). Folia Primatologica, 7, 276-283.

Groves, C. 1968. A new subspecies of white handed gibbon from northern Thailand. Hylobates lar carpenteri new sub-species. Proceedings Biological Society Washington, 81, 625-628.

Groves, C. 1972. Systematics and phylogeny of the gibbons. In Gibbon and Siamang (Ed. D. Rumbaugh), Vol. 1, pp. 1-89. Karger, Basel.

Gulik, R.H. van. 1967. The Gibbon in China. Brill, Leiden.

Haimoff, E.H., Yang, X.-J., He, S.-J. and Chen, N. 1987a.

Gibbons in Yunnan Province, China
A census and survey of wild black-crested gibbons (Hylobates concolor concolor) in Yunnan Province, People's Republic of China. Folia Primatologica (in press).

Haimoff, E.H. Yang X.-J., He, S.-J. and Chen, N. 1987b. Preliminary observations on wild black-crested gibbons (Hylobates concolor concolor) in Yunnan Province, People's Republic of China. Primates (in press).

Li, Z and Lin, Z. 1983. Distribution and classification of living primates in Yunnan Province. Zoological Research. 4, $111-120$.

Liu, Z., Yu, S. and Yuan, X. 1984. Resources of the Hainan black gibbon and its present situation. Chinese Wildlife, 6 , $1-4$.

Quan, G., Wang, S. and Zhang, Y. 1981. On the recent status and conservation of primates in China. Acta Theriologica Sinica, 1,99-104.

Tan, B. 1985. The status of primates in China. Primate Conservation, 5, 63-81.

Xu, N., Liu, Z., Liao, W., Li, S., Yu, S., Zhou, Y., Deng, J. and Guan, G. 1983. The Birds and Mammals of Hainan Island. Scientific Publishing Co., Beijing.

Yang, D., Mu, W. and Yang, H. 1982. The life of gibbons. Nature Quarterly, 1982, $105-110$.

Zhang, Y., Wang, S. and Quan, G. 1981. On the geographical distribution of primates in China. Joumal of Human Evolution, 10, 215-226.

Elliott H. Haimoff. Biology Department, UCLA. Los Angeles, CA 90024, USA.

Yang Xiao-Jun, He Swing-Jing and Chen Nan, Kunming Institute of Zoology, Academia Sinica Kunming. Yunnan Province, People's Republic of China. 